\title{
ERRATUM
}

\section{Erratum to: Some engineering geological effects of drought: examples from the UK}

\author{
A. Brian Hawkins
}

Published online: 30 May 2013

(C) Springer-Verlag Berlin Heidelberg 2013

\section{Erratum to: Bull Eng Geol Environ (2013) 72:37-59 \\ DOI 10.1007/s10064-013-0458-7}

The Editor of the journal would like to correct the errors in the original publication as specified below:

The corrected Fig. 22 is given opposite:

The caption of Fig. 23 should read:

Comparison between groundwater level in the summer and winter of 1991 with distance from a mature oak tree on the Oxford Clay at Melksham.

The caption of Fig. 24 should read:

Schematic representation of the different effects of drought on grassland areas on the sunny/shaded sides of a house.

The caption of Fig. 25 should read:

Temperature, soil moisture deficit, ground movement and fracture rate for a pipeline experiment undertaken in the Kimmeridge Clay at Swindon (modified from Owen et al. 1992).
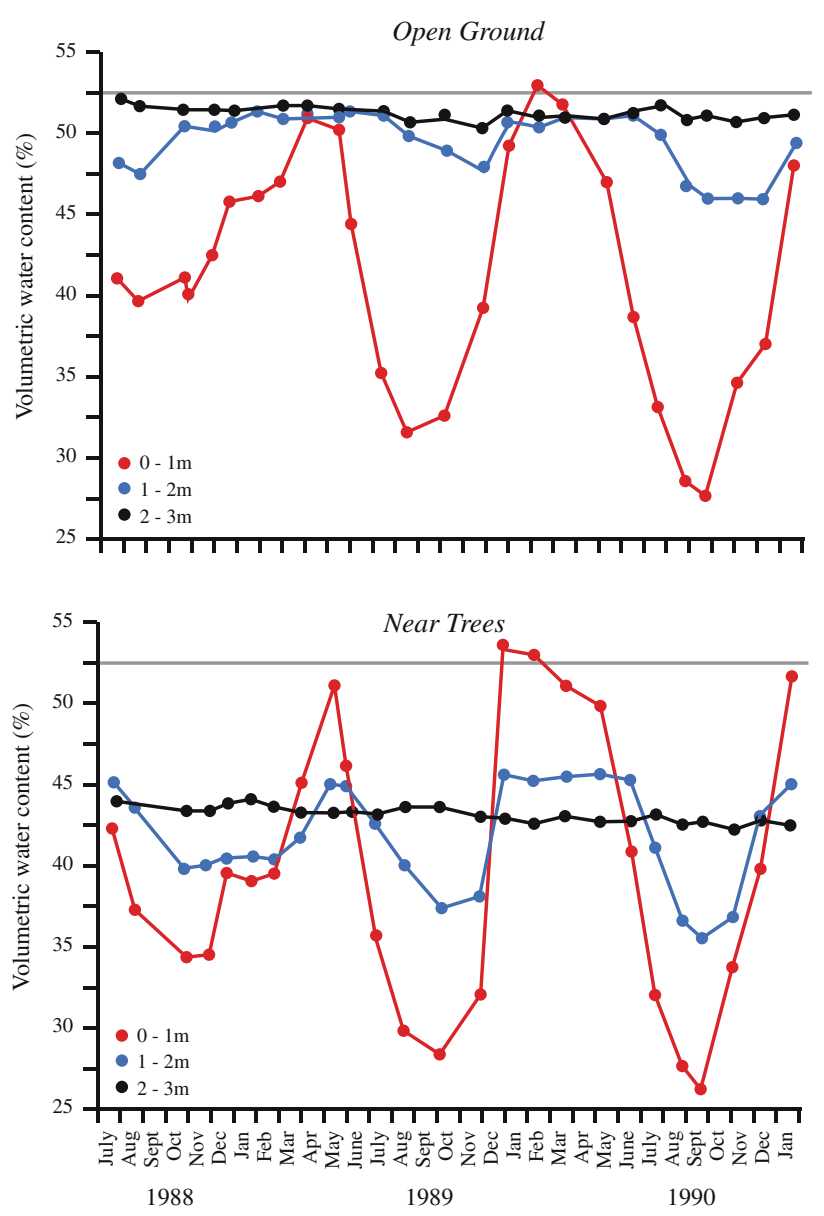

Fig. 22 Variations in volumetric moisture content with depth in open ground and close to trees during the dry period in the late 1980s/early 1990s (modified from Freeman et al. 1992a) doi:10.1007/s10064-013-0458-7.

A. B. Hawkins $(\square)$

University of Bristol, c/o Charlotte House, 22 Charlotte Street,

Bristol BS1 5PZ, UK

e-mail: brian_hawkins@btconnect.com 